Gut, 1974, 15, 870-874

\title{
Measuring the response of the jejunal mucosa in adult coeliac disease to treatment with a gluten-free diet
}

\author{
B. L. CHAPMAN ${ }^{1}$, K. HENRY, F. PAICE, N. F. COGHILL, AND J. S. STEWART
}

From the Department of Medicine, West Middlesex Hospital, Isleworth, Middlesex, the Department of Morbid Anatomy, Royal Postgraduate Medical School, Hammersmith Hospital, London, and the Medical Research Council Cyclotron Unit, Hammersmith Hospital, London

SUMMARY A previously described technique for measuring changes in the architecture of the small intestinal mucosa was used to measure the long-term response in six patients with adult coeliac disease to treatment with a gluten-free diet. All had flat or flat-with-mosaic jejunal mucosae before treatment and were subsequently believed to keep strictly to a gluten-free diet. They were followed for between four and 14 months from the start of treatment. The ratio of the area of surface epithelium to that of crypt epithelium ('area ratio') invariably increased following gluten withdrawal, but did not begin to do so until after several weeks of treatment. No patient attained complete histological normality within the limited period of observation, which was never more than 14 months. In one of the three patients followed for a year or more the area ratio increased to within the control range, and in two of these three the ratio was about 10 times the pretreatment ratio. There was a highly significant linear correlation between area ratio and time on the diet $(r=0.775, P<0.005)$.

The surface cell height measurements for these patients, by contrast, rose steeply and almost invariably during the first few weeks of treatment, but after that they fluctuated without further significant change. It is suggested that the two methods of measurement were complementary to each other, surface cell height being useful while the patient was in hospital on a rigidly strict diet, and the area ratio after return home, when minor dietary lapses were almost invariable.

We have previously described a new technique for examining small intestinal biopsies, developed to measure the long-term mucosal response of coeliac patients to treatment with a gluten-free diet (Chapman, Henry, Paice, Stewart, and Coghill, 1972, 1973). This method was based on the observation (Doniach and Shiner, 1957) that in coeliac disease there is a decrease in the amount of surface epithelium and an increase in the crypt epithelium. The areas occupied by the surface and crypt epithelium in proximal jejunal biopsies were measured with a television image analyser, and the ratio of the surface cell area to the crypt cell area was expressed as the 'area ratio'. The principles on which this method depends (Williams, 1972; Chapman et al, 1973) were enunciated by Delesse (1848) and by Chalkley (1943) as quoted by Dunnill (1972).

1 Present address: Royal Newcastle Hospital, Newcastle, NSW 2300, Australia.

Received for publication 17 July 1974.
The mean ( \pm SD) area ratio was $2.27 \pm 0.41$ in control mucosae, but only $0.24 \pm 0.07$ in untreated flat coeliac mucosae (Chapman et al, 1973). This highly significant $(P<0.001)$ ten-fold difference was greater than that for any similar measurements previously reported. We suggested that the narrow range of values found for the flat mucosae, together with the great differences between these and the control mucosae, would give plenty of room to follow the serial changes in the coeliac mucosa as it recovered on a gluten-free diet. We now present the results of such a follow-up study.

Patients, Materials, and Methods

The criteria for the diagnosis of coeliac disease and the methods employed for jejunal biopsy, the derivation of the area ratio, and the measurement of surface cell height were as described by Chapman et al (1973). The subjects of the present study were six 
previously untreated adult coeliac patients who kept completely or almost completely to a gluten-free diet during follow-up periods of from four to 14 months. Before treatment each patient had a flat or flat-withmosaic jejunal mucosa under the dissecting microscope (Holmes, Hourihane, and Booth, 1961 ; Booth, Stewart, Holmes, and Brackenbury, 1962) and 'subtotal villous atrophy' on histological examination (Shiner and Doniach, 1960). All patients improved clinically, haematologically, biochemically, and histologically when treated with a gluten-free diet.

One patient appeared to have multiple jejunal diverticula as well as adult coeliac disease, but these were no longer present after four months of gluten withdrawal (Chapman and Stewart, 1973).

To ensure that the patients kept strictly to their gluten-free diet, a part-time research dietitian was employed to instruct them in the diet and to supervise its implementation. The patients started the diet while still in the ward and were discharged home when they, and where necessary their spouses, seemed to understand the diet. The detailed assessment of early response was observed before the patients left hospital, in this study usually after two or three weeks. On return home they were seen regularly by the research dietitian. She rapidly achieved a good rapport with the patients, helped them with the diet, and reported problems and lapses to us. It was found that some, even of the most meticulous patients, occasionally took a little gluten, either accidentally or knowingly.

Patients were included in the series only if they appeared to be keeping strictly to the gluten-free diet. The assessment of their strictness in keeping to the diet was based on the results of questioning at follow-up visits to the malabsorption clinic and on the research dietitian's reports following her domiciliary visits. These criteria were supplemented by indirect evidence based on a fall in the serum and redcell folate levels (Hoffbrand, 1974).

\section{Results}

In the six adult coeliac patients considered to be on a completely, or almost completely, gluten-free diet, the general trend for the area ratios was to increase progressively with the length of time on the diet (fig 1). Although the area ratios for individual patients fluctuated in the early weeks of treatment, they subsequently always increased. In one of the three patients observed for 12 months or more, the area ratio entered the range previously found for control mucosae (fig 1). Two of these three patients achieved an area 1atio about ten times as high as that before treatment $(10 \cdot 1: 1$ and $11 \cdot 6: 1)$.

Overall, the relationship between area ratio and time on a gluten-free diet was a highly significant linear correlation (fig 2). According to the coefficient of determination $\left(\mathrm{r}^{2}\right), 60 \cdot 1 \%$ of the variation in area ratio was 'explained' by variation in time on a glutenfree diet. The area ratio to be expected for a given number of days on the diet may be calculated from the regression equation $y=0.003 x+0.269$, where $x=$ no. of days on the diet and $y=$ area ratio.

Contrasting with the pattern of responses for area

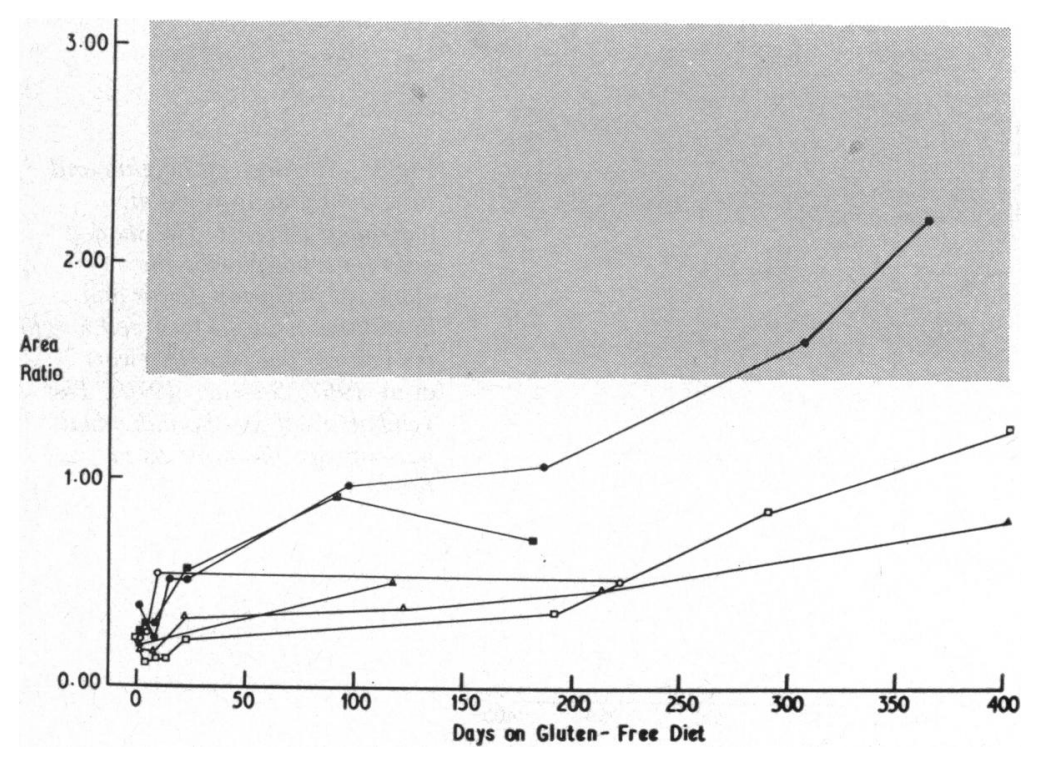

Fig 1 Area ratios and time on a gluten-free diet: individual patients. The shaded area represents twice the standard deviation above and below the mean area ratio for control mucosae (Chapman et al, 1973). 


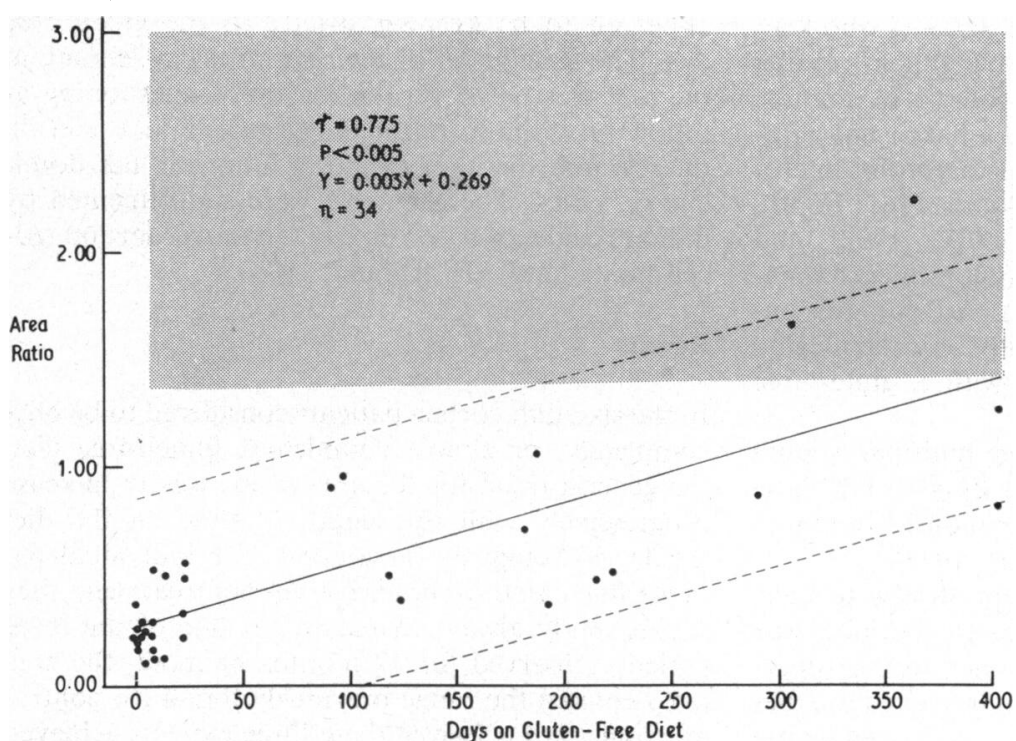

Fig 2 Area ratios and time on a gluten-free diet: linear correlation and regression analysis. The broken lines represent twice the standard error of estimate above and below the calculated regression line. The shaded area represents twice the standard deviation above and below the mean area ratio for control mucosae (Chapman et al, 1973). ratio (fig 1) was the pattern for surface cell height (fig 3). In the first few weeks of treatment the cell height increased rapidly and consistently with the partial exception of one patient who showed a fall in surface cell height at 21 days, five days after discharge from hospital. After the first weeks, however, the surface cell height fluctuated in all patients and seldom increased much further. Although there was a highly significant linear correlation between surface cell height and time on the gluten-free diet ( $r=0.504, P<0.005)$, according to the coefficient of determination only $25.4 \%$ of the variation in surface cell height was 'explained' by variation in time on the diet.

No patient achieved a jejunal mucosa that was completely normal histologically during the limited time of observation which was never more than 14 months.

\section{Discussion}

These results show that the ratio of the areas of sur-

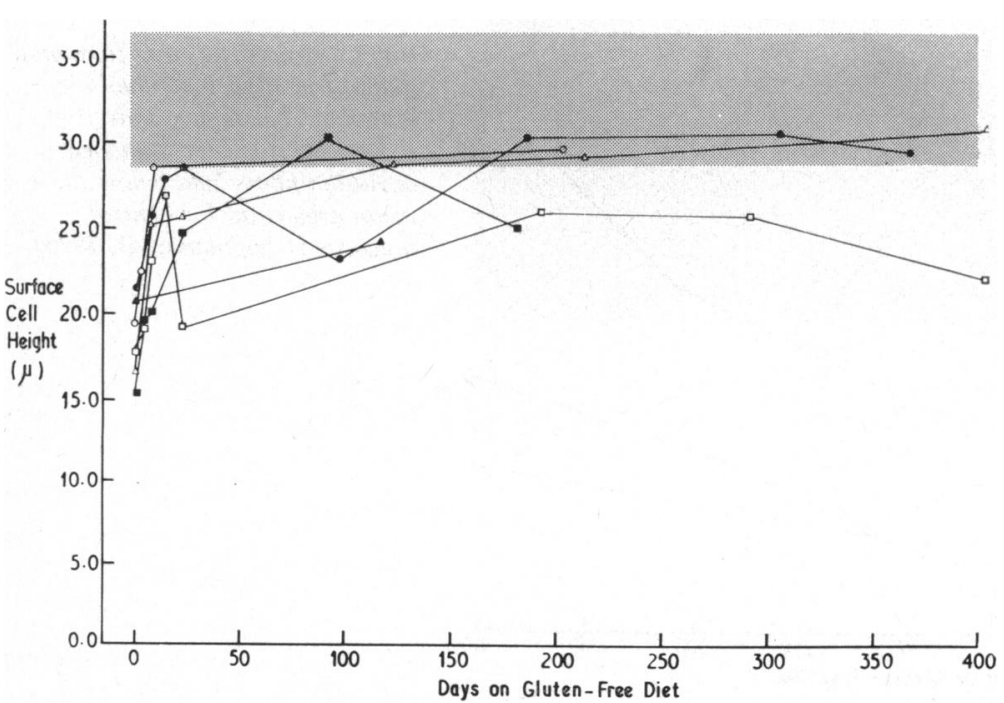

Fig 3 Surface cell heights and time on a gluten-free diet: individual patients. The shaded area represents twice the standard deviation above and below the mean surface cell height for control mucosae (Stewart et al, 1967; Stewart, 1970). The symbols used for the individual patients are the same as in figure 1. 
face and crypt epithelium in proximal jejunal biopsies is useful for measuring the long-term mucosal response of patients with adult coeliac disease to treatment with a gluten-free diet. In four patients the area ratio increased consistently with time on the diet after the first few weeks. In the remaining two the initial increase was not maintained in spite of apparently obsessional adherence to the diet. Overall, there was a highly significant linear correlation between the area ratio and the length of time on the diet, and $60 \%$ of the variation in the ratio was 'explained' by variation in the time. This correlation was much closer than that for surface cell height, the most reliable of the conventional measurements (Shiner and Doniach, 1960; Yardley, Bayless, Norton, and Hendrix, 1962; Madanagopalan, Shiner, and Rowe, 1965; Stewart, Pollock, Hoffbrand, Mollin, and Booth, 1967; Pollock, Nagle, Jeejeebhoy, and Coghill, 1970). Nevertheless, the surface cell height did increase rapidly in the early weeks of treatment, while patients were in the ward on a rigidly strict diet. Only after that did it fluctuate without further net increase. The early variability of the area ratio may be due in part to errors inherent in this method of measurement, and in part to asynchronous changes in the areas of surface and crypt epithelium when gluten is first withdrawn.

Thus surface cell height was valuable for measuring the early response to treatment. Area ratio, on the other hand, was suitable for following the response over longer periods of time. The two measurements are complementary. It seems that the area ratios reflect multiple dimensions of the mucosal architecture which continue to change for a long time, while surface cell height is only a single dimension and has a limit which is reached relatively soon after the withdrawal of gluten (Bayless, Yardley, Norton, and Hendrix, 1962; Yardley et al, 1962; Madanagopalan et al, 1965; Booth, Stewart, and Olsen, 1967; Stewart et al, 1957; Pollock et al, 1970; Trier and Browning, 1970). For these reasons, as well as the rapid decrease in cell height when gluten is ingested (Bayless et al, 1962; Bayless, Rubin, Topping, Yardley, and Hendrix, 1970; Pollock et al, 1970), we expect that surface cell height will prove superior to area ratio for measuring the response of a treated coeliac mucosa to an acute gluten challenge.

Most of the problems with the area ratio technique are similar to those with the standard methods. They include the error in sampling due to the small size of the piece of tissue examined, the necessity for correct orientation of the specimens, the strictness of the patients' adherence to the gluten-free diet, and other variations of unknown cause such as 'degree of responsiveness'. Sampling error, once the tissue is obtained, is probably less with this technique than with the surface cell height measurements because a whole section is examined rather than selected cells. Nevertheless many sections were rejected as unsuitable for analysis, because of imperfect orientation.

Another practical problem with the area ratio technique is the probable cost of the area-measuring instrument, still in its developmental stage of production. Simple visual assessment of serial biopsy specimens taken during gluten withdrawal provides an approximate indication of mucosal response. What strikes the eye is the improvement in surface cells and, later, the appearance of villi rather than changes in the ratio of surface to crypt cells which are difficult for the eye to assimilate.

As far as diet is concerned, even with the aid of the research dietitian who visited the patients in their own homes and sometimes detected lapses which they had not noticed, we could not ensure that all gluten was excluded. This point is important, and the maximum possible rate of increase of the area ratio may be greater than the present results suggest. Furthermore, if the patients studied had no significant gluten during the follow-up period, the fluctuations in surface cell height must have been due to factors other than gluten intake such as sensitivity to substances other than gluten.

Few published reports give serial measurements of the long-term response of the coeliac mucosa to treatment with a gluten-free diet. Madanagopalan et al (1965) used the ratio of villous height to total mucosal thickness in order to measure the response of eight coeliac patients during follow-up periods sometimes in excess of two years. Although this ratio increased overall with time on the diet and although in one patient it returned to the normal range, its value was often about the same after many months on the diet, or even lower than before the start of treatment. Booth et al (1967) demonstrated, in frequent serial biopsies of a patient with coeliac disease, the rapid response to treatment of the surface cell height and the slower improvements of the other dimensions of mucosal structure. Similar results were obtained in 17 patients by Pollock et al (1970) and in five patients treated with prednisolone on a gluten-containing diet by Wall, Douglas, Booth, and Pearse (1970). Peña, Truelove, and Whitehead (1972) showed in 10 patients that the area-to-volume ratio of the jejunal mucosa (Dunnill and Whitehead, 1972) was significantly higher after treatment with a gluten-free diet than before. In two of their patients who had serial biopsies after the start of treatment, the area-to-volume ratio increased, respectively, to four and five times its pretreatment value. When one 
of these patients was subsequently also treated with steroids the ratio increased still further, to almost eight times its original value. In the present series two of the three patients observed for 12 months or more had area ratios 10 or 11 times as high as before treatment.

One of us (BLC) was in receipt of a research grant from the North-West Metropolitan Regional Hospital Board to whom we are grateful for support. We are indebted to Miss J. Fletcher, chief dietitian, Mrs Eileen McKay, the research dietitian, Sister Jennifer Jones and her nursing staff, and Miss Susan Robinson, the medical artist.

\section{References}

Bayless, T. M., Rubin, C. E., Topping, T. M., Yardley, J. H., and Hendrix, T. R. (1970). Morphologic and functional effects of gluten feeding on jejunal mucosa in coeliac disease. In Coeliac Disease: Proceedings of an International Conference held at the Royal Postgraduate Medical School, London, 1969, edited by C. C. Booth and R. H. Dowling, pp. 76-90. Churchill Livingstone, Edinburgh and London.

Bayless, T. M., Yardley, J. H., Norton, J. H., and Hendrix, T. R. (1962). Adult celiac disease: rapid sequential changes in jejuna mucosa with alterations of dietary gluten. J. clin. Invest., 41, 1344.

Booth, C. C., Stewart, J. S., Holmes, R., and Brackenbury, W. (1962). Dissecting microscope appearances of intestinal mucosa. In Intestinal Biopsy (Ciba Foundation Study Group No. 14), edited by G. E. W. Wolstenholme and M. P. Cameron, pp. 2-23. Churchill, London.

Booth, C. C., Stewart, J. S., Olsen, E., et al (1967). A case of Crohn's disease in a patient with treated adult coeliac disease. (Clinicopathological Conference). Brit. med. J., 4, 222-226.

Chalkley, H. W. (1943). Method for the quantitative morphologic analysis of tissues. J. nat. Cancer Inst., 4, 47-53.

Chapman, B. L., Henry, K., Paice, F., Stewart, J. S., and Coghill, N. F. (1972). A new technique for examining intestinal biopsies. Abstract in the Proceedings of the British Society of Gastroenterology. Gut, 13, 846.
Chapman, B. L., Henry, K., Paice, F., Stewart, J. S., and Coghill, N. F. (1973). A new technique for examining intestinal biopsies. Gut, 14, 905-909.

Chapman, B. L., and Stewart, J. S. (1973). Adult coeliac disease and multiple small bowel diverticula. Proc. roy. Soc. Med., 66, 11-12.

Delesse, M. (1848). Procédé mécanique pour determiner la composition des roches. Ann. Mines (Paris), 13, 378-388.

Doniach, I., and Shiner, M. (1957). Duodenal and jejunal biopsies. II Histology. Gastroenterology, 33, 71-86.

Dunnill, M. S. (1972). Counting techniques in morbid anatomy. Proc roy. Soc. Med, 65, 537-539.

Dunnill, M. S., and Whitehead, R. (1972). A method for the quantitation of small intestinal biopsy specimens. J. clin. Path., 25, 243 246.

Hoff brand, A. V. (1974). Anaemia in adult coeliac disease. Clin. Gastroent., 3, 71-89.

Holmes, R., Hourihane, D. O'B., and Booth, C. C. (1961). Dissectingmicroscope appearances of jejunal biopsy specimens from patients with 'idiopathic steatorrhoea'. Lancet, 1, 81-83.

Madanagopalan, N., Shiner, M., and Rowe, B. (1965). Measurements of small intestinal mucosa obtained by peroral biopsy. Amer. J. Med., 38, 42-53.

Peña, A. S., Truelove, S. C., and Whitehead, R. (1972). Disaccharidase activity and jejunal morphology in coeliac disease. Quart. J. Med., n.s., 41, 457-476.

Pollock, D. J., Nagle, R. E., Jeejeebhoy, K. N., and Coghill, N. F (1970). The effect on jejunal mucosa of withdrawing and adding dietary gluten in cases of idiopathic steatorrhoea. Gut, 11, 567 575.

Shiner, M., and Doniach, I. (1960). Histopathologic studies in steatorrhea. Gastroenterology, 38, 419-440.

Stewart, J. S. (1970). A study of intestinal mucosal structure and absorptive function in adult coeliac disease. Doctoral Thesis, University of London.

Stewart, J. S., Pollock, D. J., Hoff brand, A. V., Mollin, D. L., and Booth, C. C. (1967). A study of proximal and distal intestinal structure and absorptive function in idiopathic steatorrhoea. Ouart. J. Med., n.s., 36, 425-444.

Trier, J. S., and Browning, T. H. (1970). Epithelial-cell renewal in cultured duodenal biopsies in celiac sprue. New Engl. J. Med. $283,1245-1250$

Wall, A. J., Douglas, A. P., Booth, C. C., and Pearse, A. G. E. (1970). Response of the jejunal mucosa in adult coeliac disease to oral prednisolone. Gut, 11, 7-14.

Williams, E. D. (1972). Automated histoquantitation studies of bone. Proc. roy. Soc. Med., 65, 539-541.

Yardley, J. H., Bayless, T. M., Norton, J. H., and Hendrix, T. R. (1962). Celiac disease: a study of the jejunal epithelium before and after a gluten-free diet. New Engl.J. Med., 267, 1173-1179. 